OPEN ACCESS

Edited by:

Martin Maiers,

National Marrow Donor Program,

United States

Reviewed by:

Ketevan Gendzekhadze,

City of Hope National Medical Center,

United States

Johannes Schetelig,

Universitätsklinikum Carl Gustav

Carus, Germany

*Correspondence:

Paul J. Norman

paul.norman@ucdenver.edu

tThese authors have contributed equally to this work

Specialty section:

This article was submitted to NK and Innate Lymphoid Cell Biology,

a section of the journal

Frontiers in Immunology

Received: 04 December 2019

Accepted: 11 March 2020

Published: 02 April 2020

Citation:

Alicata C, Ashouri E,

Nemat-Gorgani N, Guethlein LA, Marin WM, Tao S, Moretta L,

Hollenbach JA, Trowsdale J,

Traherne JA, Ghaderi A, Parham P and Norman PJ (2020) KIR Variation in

Iranians Combines High Haplotype and Allotype Diversity With an

Abundance of Functional Inhibitory

Receptors. Front. Immunol. 11:556.

doi: 10.3389/fimmu.2020.00556

\section{KIR Variation in Iranians Combines High Haplotype and Allotype Diversity With an Abundance of Functional Inhibitory Receptors}

\author{
Claudia Alicata ${ }^{1 \dagger}$, Elham Ashouri ${ }^{2,3,4,5+}$, Neda Nemat-Gorgani ${ }^{2,3,6}$, Lisbeth A. Guethlein ${ }^{2,3}$, \\ Wesley M. Marin ${ }^{7}$, Sudan Tao ${ }^{8,9}$, Lorenzo Moretta ${ }^{1}$, Jill A. Hollenbach ${ }^{7}$, John Trowsdale ${ }^{6}$, \\ James A. Traherne ${ }^{6}$, Abbas Ghaderi ${ }^{5}$, Peter Parham ${ }^{2,3}$ and Paul J. Norman ${ }^{2,3,9 *}$ \\ ${ }^{1}$ Department of Immunology, IRCCS Bambino Gesù Children's Hospital, Rome, Italy, ${ }^{2}$ Department of Structural Biology, \\ Stanford University School of Medicine, Stanford, CA, United States, ${ }^{3}$ Department of Microbiology and Immunology, \\ Stanford University School of Medicine, Stanford, CA, United States, ${ }^{4}$ Hematology-Oncology and Stem Cell Transplantation \\ Research Center, Tehran University of Medical Sciences, Tehran, Iran, ${ }^{5}$ School of Medicine, Shiraz Institute for Cancer \\ Research, Shiraz University of Medical Sciences, Shiraz, Iran, ${ }^{6}$ Division of Immunology, Department of Pathology, University \\ of Cambridge, Cambridge, United Kingdom, ${ }^{7}$ Department of Neurology, University of California, San Francisco, San \\ Francisco, CA, United States, ${ }^{8}$ Blood Center of Zhejiang Province, Hangzhou, China, ${ }^{9}$ Division of Personalized Medicine, \\ Department of Immunology and Microbiology, University of Colorado, Anschutz Medical Campus, Aurora, CO, United States
}

Natural killer (NK) cells are innate lymphocytes that eliminate infected and transformed cells. They discriminate healthy from diseased tissue through killer cell lg-like receptor (KIR) recognition of HLA class I ligands. Directly impacting NK cell function, KIR polymorphism associates with infection control and multiple autoimmune and pregnancy syndromes. Here we analyze KIR diversity of 241 individuals from five groups of Iranians. These five populations represent Baloch, Kurd, and Lur, together comprising 15\% of the ethnically diverse Iranian population. We identified 159 KIR alleles, including 11 not previously characterized. We also identified 170 centromeric and 94 telomeric haplotypes, and 15 different KIR haplotypes carrying either a deletion or duplication encompassing one or more complete KIR genes. As expected, comparing our data with those representing major worldwide populations revealed the greatest similarity between Iranians and Europeans. Despite this similarity we observed higher frequencies of KIR3DL 1*001 in Iran than any other population, and the highest frequency of HLA-B*51, a Bw4-containing allotype that acts as a strong educator of KIR3DL $1^{*} 001^{+}$ NK cells. Compared to Europeans, the Iranians we studied also have a reduced frequency of $3 D L 1 * 004$, which encodes an allotype that is not expressed at the NK cell surface. Concurrent with the resulting high frequency of strong viable interactions between inhibitory KIR and polymorphic HLA class I, the majority of KIR-A haplotypes characterized do not express a functional activating receptor. By contrast, the most frequent $K I R-B$ haplotype in Iran expresses only one functional inhibitory KIR and the maximum number of activating KIR. This first complete, high-resolution, characterization of the KIR locus of Iranians will form a valuable reference for future clinical and population studies.

Keywords: NK cells, KIR, HLA class I, Iranian populations, immune diversity 


\section{INTRODUCTION}

Natural killer (NK) cells are essential for human immunity to infection and cancer, and for successful reproduction (1, 2). To discriminate diseased from healthy tissue cells, NK cells express an array of inhibiting and activating cell surface receptors $(3,4)$. Prominent among these receptors are the killer cell immunoglobulin like receptors (KIR), which educate and modulate NK cell function through interaction with HLA class I (5, 6). KIR are highly polymorphic, a geneticallydetermined variation that directly impacts NK cell function, and susceptibility to disease $(7,8)$.

The KIR locus spans 150-350 kbp of chromosome 19q13.4 (9). The locus is distinguished by structural and sequence diversity of the 13 constituent genes (KIR2DL1, KIR2DL2/L3, KIR2DL4, KIR2DL5A, KIR2DL5B, KIR2DS1, KIR2DS2, KIR2DS3, KIR2DS4, KIR2DS5, KIR3DL1/S1, KIR3DL2, and KIR3DL3) and two pseudogenes (KIR2DP1 and KIR3DP1) $(10,11)$. KIR have either two (2D) or three (3D) specificity-determining immunoglobulinlike domains and a long (L) or short (S) tail (12). KIR having a long cytoplasmic tail are inhibitory, whereas those having a short cytoplasmic tail are activating. The one exception is KIR2DL4, which can exhibit inhibitory or activating function (13-15). The KIR locus segregates in two main haplotype forms that are maintained in all human populations by balancing selection (16). The KIR-A haplotypes have a fixed number of predominantly inhibitory receptors, whereas the KIR-B haplotypes are characterized by a variable number of both activating and inhibitory receptors. Further distinguishing KIR$A$ and $-B$ haplotypes are their characteristic alleles (17). KIR$A$ haplotypes are associated with controlling infectious disease and cancer, but confer susceptibility to reproductive disorders, whereas $K I R-B$ haplotypes are associated with protection from reproductive disorders $(1,7)$. Additionally, haploidentical transplantation therapy for leukemia has an increased success rate when the stem cell donors carry $K I R-B$ haplotypes $(18,19)$.

Polymorphism of KIR affects cell surface expression, ligand specificity, ligand binding strength, and intracellular signaling (20-25). All these factors affect the capacity of NK cells to recognize and kill target cells. Because both KIR polymorphism and associated diseases are unevenly distributed worldwide, it is critical to fully gauge the genetic diversity of KIR in welldefined human populations. Despite this importance, only a few populations have been studied to high resolution, principally due to the complexity of the KIR locus. These studies have focused on representative populations of Amerindians (Yucpa) (26), divergent African groups (27-29), Europeans (30, 31), East Asians (Japanese) (32), and Oceanians (Māori) (33). Together, they show how KIR allele and haplotype diversity varies dramatically between human populations and highlight the importance of extending KIR allele analysis to represent all ethnicities and geographical areas. In this regard, our recent analysis of $H L A$ allelic diversity in Iran revealed the highest frequencies of $H L A-B^{*}$ 51:01 worldwide (34). HLA-B*51 contains the Bw4 epitope and interacts $\operatorname{KIR} 3 \mathrm{DL} 1(35,36)$. In the present study we fully characterize KIR locus diversity of the same cohort of Iranian individuals.

\section{MATERIALS AND METHODS}

\section{Study Population}

The KIR locus diversity of three indigenous Iranian populations was determined to high-resolution by analyzing genomic DNA from 241 healthy unrelated donors (34). The populations studied represent Baloch, Kurd, and Lur, together comprising 15\% (12 million individuals) of the ethnically diverse Iranian population. Studied were 160 Lurs and 48 Kurds, from the Zagros Mountains at the west of Iran, and 33 Baloch from the southeast of Iran. The Lur population included 64 individuals from the city of Khoramabad in the province of Lorestan, 81 from Yasuj in the province of Kohgiluyeh and Boyer-Ahmad, and 15 from Lordegan in the province of Chaharmahal and Bakhtiari. The samples from Kurds were collected from the city of Sanandaj. With the exception of the Baloch, the HLA class I alleles were described previously (34). The ancestors of every individual studied had been part of their respective population for at least two generations. Sample collection was approved by the Medical Research Ethics Committee of Shiraz University of Medical Sciences. All participants gave informed consent. Banked, deidentified samples were used for this study.

\section{Library Preparation and Enrichment}

Genomic DNA was prepared by shearing with sonication and the KIR genomic region was enriched from the genomic libraries using a pool of oligonucleotide probes as described (37). The enriched fragments were subjected to paired-end sequencing using Illumina's MiSeq instrument and V3 sequencing chemistry (Illumina, La Jolla CA). The sequencing read length was $2 \times$ $300 \mathrm{bp}$.

\section{Next Generation Sequence Data Processing and Analysis}

Sequence reads specific to the KIR region were identified and harvested using Bowtie 2 (38). KIR genotyping was performed using the Pushing Immunogenetics to the Next Generation pipeline (37). This pipeline generates a high-resolution KIR gene content and allele level genotype. It can also identify previously unreported single nucleotide polymorphisms (SNPs) and recombinant alleles. Novel allele sequences were analyzed by visual inspection: reads specific to the relevant gene were isolated by bioinformatics filtering, aligned to the closest reference allele using MIRA 4.0.2 (39), and inspected using Gap4 of the Staden package (40) or Integrative Genomics Viewer (41).

\section{Allele and Haplotype Frequencies}

Allele frequencies were calculated by direct counting. The composition and frequencies of KIR haplotypes were determined at the allelic level using PHASE 2.1 (42). The following parameters for PHASE 2.1 were used: $-\mathrm{f} 1,-\mathrm{x} 5$, and $-\mathrm{d} 1$. Because of the high rate of recombination between KIR3DP1 and KIR2DL4 (9), we performed two separate PHASE runs, one for the KIR genes of the centromeric region and one for telomeric KIR genes. Genes analyzed were KIR3DL3, 2DS2, $2 D L 2 / 3,2 D L 5 A$ and $B, 2 D S 3 / 5,2 D P 1,2 D L 1,2 D L 4,3 D L 1 / S 1$, 


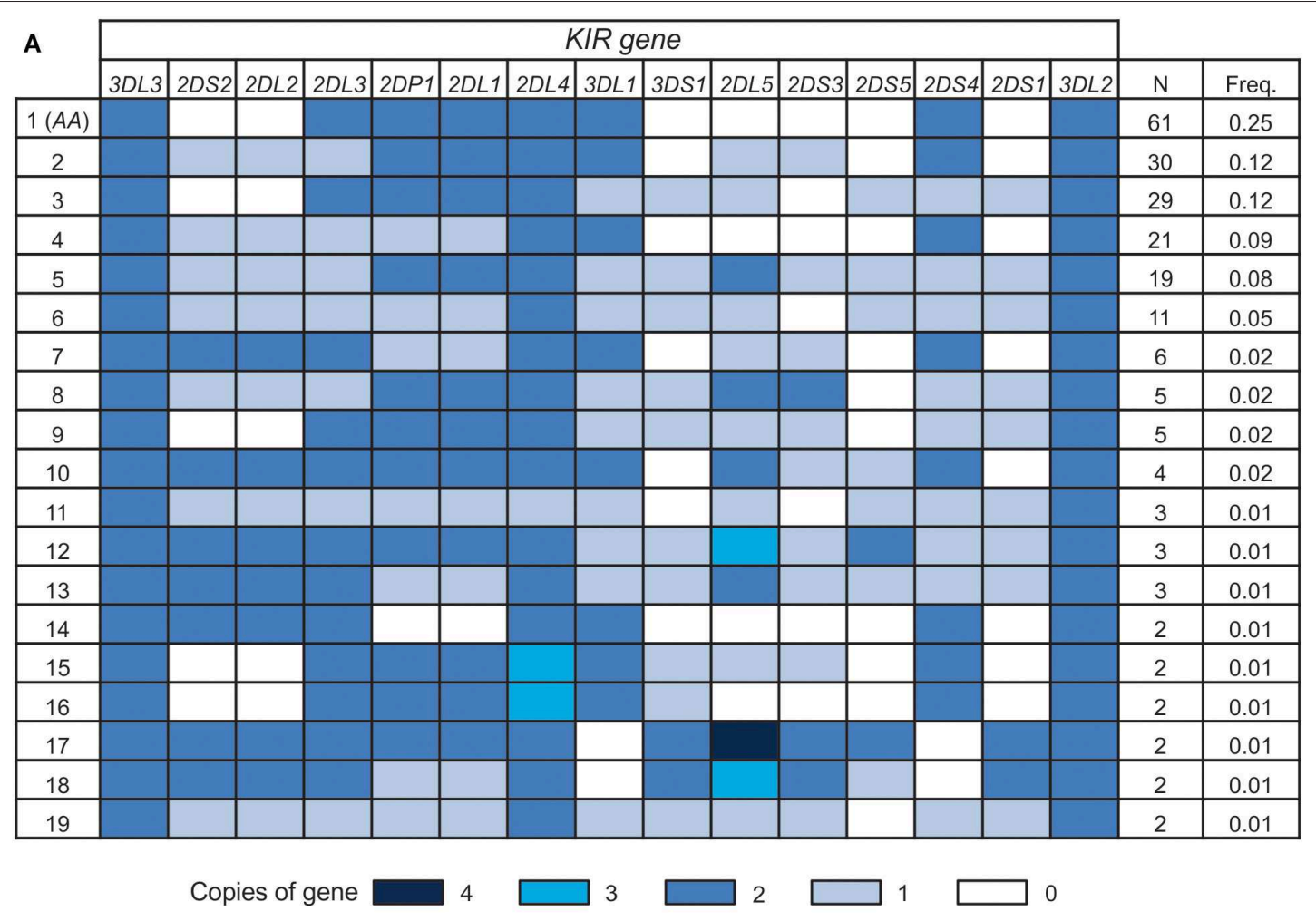

B
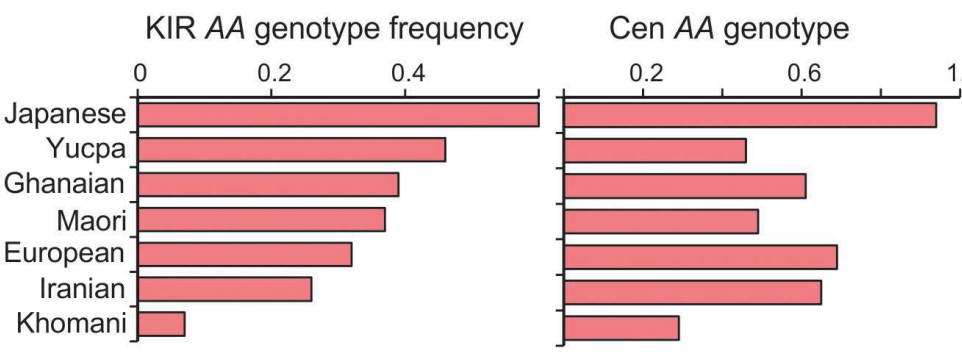

Tel $A A$ genotype

C

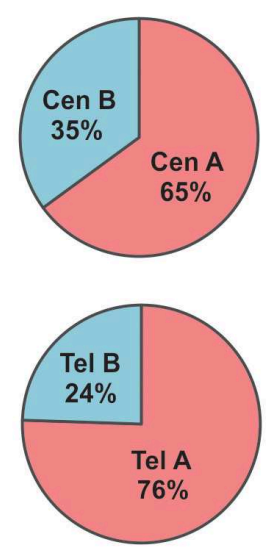

D

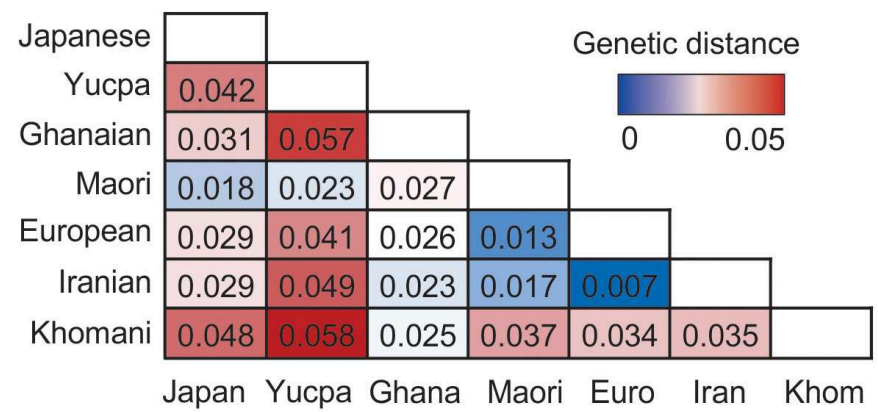

E

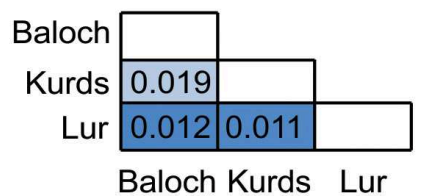

FIGURE 1 | Iranian KIR genotypes resemble those of Europeans. (A) Shows KIR gene copy-number genotypes ordered by the total number observed across the five Iranian populations. Only genotypes present in more than one individual are shown. Colored boxes indicate the number of copies of the gene, as given in the key 
FIGURE 1 | below. A white box indicates the gene is absent. (B) Frequency of the full KIR AA (left), Cen AA (center), and Tel $A A$ (right) genotypes across seven representative world populations, ordered by frequency of full KIR AA. The populations are Japanese $(N=115)$, Yucpa Amerindians ( $N=61)$, Ghanaians from West Africa $(N=131)$, Maori from New Zealand $(N=49)$, Europeans $(N=378)$, Iranians $(N=241)$, and Khomani from South Africa ( $N=79)$. (C) Frequency of centromeric (Cen) and telomeric (Tel) KIR A and B haplotypes in the five Iranian populations combined. (D) Genetic distance between the combined Iranian population and the six representative, populations from (B). KIR genes included are those genotyped in all the populations shown 2DL1-4, 2DS1-5, 3DL1/S1, 3DL2. (E) Genetic distance between the three Iranian populations.

$2 D S 1,2 D S 4$, and 3DL2. For each haplotype we calculated the frequency by direct counting.

\section{Statistical Analysis}

Hardy-Weinberg equilibrium proportions was examined using Fisher's exact test. Differences in frequency amongst populations were tested using $\chi^{2}$ with Bonferroni correction for the number of alleles at the respective locus. Fisher's and $\chi^{2}$ test as well as Mann-Whitney $U$-test were implemented using GraphPad Prism 7.05.

\section{Genetic Distance}

The genetic distance between Iranians and other populations was calculated using the Cavalli-Sforza model (43), implemented in GENETIX 4.05 (https://kimura.univ-montp2.fr/genetix/). The populations used were Japanese $(N=115)$ (32), Yucpa Amerindians $(N=61)$ (26), Ghanaians from West Africa $(N=$ 131) (27), Māori from New Zealand $(N=49)$ (33), Europeans $(N$ $=378)(44)$, and Khomani from South Africa $(N=79)(28)$.

\section{RESULTS}

We sequenced the KIR genes of 241 individuals from five populations, representing three groups of Iranians; the Lurs, Kurds and Baloch. The Lurs comprised individuals from the cities of Khoramabad, Lordegan and Yasuj. Only two KIR genes were present as two copies $(2 \mathrm{~N})$ in every individual, KIR3DL3 at the centromeric end of the KIR locus and KIR3DL2 at the telomeric end (Figure 1A). Every KIR haplotype in this Iranian cohort is therefore flanked by these two framework genes. The third framework gene is KIR2DL4 (9). Because eight individuals have only one copy of KIR2DL4 and six have three copies, KIR2DL4 is not present on every Iranian KIR haplotype (Figure 1A), but is likely duplicated on some haplotypes and deleted from others (45). The frequency of $K I R-A$ haplotypes varies across populations $(16,46)$. In the combined study population, the frequency of KIR AA genotypes observed is $25 \%$ (Figure 1B). Centromeric KIR-A haplotypes are present at $65 \%$ and telomeric KIR-A haplotypes at $76 \%$ (Figure 1C). The frequency of KIR $A$ haplotype homozygotes closely matches that of European populations (Figure 1B), as do genetic distance measurements calculated from the KIR genotype data (Figure 1D). In conclusion, the number and distribution of KIR gene content haplotypes in Iranians closely resemble those present in Europeans.

We determined the KIR allele frequencies in the five Iranian populations. These data are shown in Supplementary Material A and summarized in Figure 2. The allele frequencies were consistent with Hardy-Weinberg equilibrium. Among the five populations, we identified 115 inhibitory KIR alleles and 18 activating KIR alleles (Figure 2A). Also present are $12 \mathrm{KIR} 2 \mathrm{DL} 4$ alleles. Inhibitory KIR are highly polymorphic in Iranians, with 12 KIR2DL1, 9 KIR2DL2/L3, 10 KIR2DL5, 22 KIR3DL2, 18 KIR3DL1, and 44 KIR3DL3 alleles observed in total. As in other populations, the activating KIR are less polymorphic than the inhibitory KIR, with 7 KIR2DS4 alleles, 8 KIR2DS3/5 alleles, two KIR2DS1 and two KIR2DS2 alleles and one KIR3DS1 allele being seen (Figure 2A). In Iranians, KIR3DL3 is the most polymorphic KIR gene, whereas KIR2DS1 and KIR2DS2 are the least variable. In the combined population analyzed, the most frequent allele for each of the inhibitory KIR are $2 D L 1^{*} 00302,2 D L 2^{*} 00101$, 2DL3*00101, 3DL1*00101, 3DL2*00101, and 3DL3*00301, respectively (Supplementary Material A). The most common KIR2DL4 and KIR2DS4 alleles are 2DL4*00801 and 2DS4*003, respectively. For the other activating KIR (KIR2DS1-3 and 2DS5) as well as KIR2DL5, the most frequent allele observed is absence of the gene (Supplementary Material A). We did not observe any statistically significant difference in frequency of any specific KIR allele between Kurs and Lurs. We identified 11 novel $K I R$ alleles, eight being defined by amino acid substitutions, one by a synonymous substitution and two by substitutions in KIR2DP1 pseudogene (Figure 2B). All these novel alleles were observed in one or two individuals (Figure 2B). Seven of them have sequences identical to ones reported recently in a survey of more than one million registered bone marrow donors (47).

On the basis of allele composition, we defined 170 centromeric and 94 telomeric KIR haplotypes (Supplementary Materials B,C). Thus, by distinct haplotype number, the centromeric region is twice as diverse as the telomeric region. Emphasizing this difference, the 55 most frequent centromeric haplotypes account for $75 \%$ of the total haplotypes, whereas only 13 telomeric haplotypes are sufficient to account for $75 \%$ of the telomeric haplotypes (Figures 3A,B). In conclusion, the centromeric KIR region of Iranian KIR haplotypes is far more diverse than the telomeric KIR region.

Although $K I R-A$ haplotypes are more numerous and frequent than $K I R-B$ haplotypes (Figure 1), the most frequent centromeric region and the second most frequent telomeric region haplotypes are $K I R-B$ (Figures 3C,D). Together, these centromeric and telomeric segments encode only one inhibitory receptor specific for HLA class I (KIR2DL2*001). Also encoded are KIR2DL1*004, an attenuated receptor (23) and KIR3DL2*007, which has a mutation in the first ITIM of the cytoplasmic tail (48) and thus may not transmit an inhibitory signal. By contrast, the $K I R-B$ haplotype encodes three functional activating receptors (KIR2DS1, 2DS2, and 3DS1) and a full-length KIR2DL4 (*005). This combination of common centromeric and telomeric KIR-B 


\begin{tabular}{|c|c|c|c|c|c|c|c|c|c|c|c|}
\hline \multirow{3}{*}{ A } & \multirow{2}{*}{\multicolumn{2}{|c|}{$\begin{array}{l}\text { Baloch } \\
(\mathrm{N}=33)\end{array}$}} & \multirow{2}{*}{\multicolumn{2}{|c|}{$\begin{array}{r}\text { Kurds } \\
(\mathrm{N}=48)\end{array}$}} & \multicolumn{6}{|c|}{ Lurs } & \multirow[b]{3}{*}{ Total } \\
\hline & & & & & \multicolumn{2}{|c|}{$\begin{array}{c}\text { Lorestan } \\
(\mathrm{N}=64)\end{array}$} & \multicolumn{2}{|c|}{$\begin{array}{l}\text { Lordegan } \\
(\mathrm{N}=15)\end{array}$} & \multicolumn{2}{|c|}{$\begin{array}{l}\text { Yasuj } \\
(\mathrm{N}=81)\end{array}$} & \\
\hline & $\mathrm{k}$ & $\mathrm{H}$ & $\mathrm{k}$ & $\mathrm{H}$ & k & $\mathrm{H}$ & $\mathrm{k}$ & $\mathrm{H}$ & $\mathrm{k}$ & $\mathrm{H}$ & \\
\hline $2 D L 1$ & 7 & 0.94 & 8 & 0.81 & 8 & 0.85 & 7 & 0.86 & 9 & 0.68 & 12 \\
\hline $2 D L 2 / 3$ & 5 & 0.76 & 6 & 0.67 & 5 & 0.75 & 5 & 0.73 & 8 & 0.76 & 9 \\
\hline $2 D L 4$ & 8 & 0.79 & 8 & 0.81 & 8 & 0.82 & 8 & 0.93 & 10 & 0.82 & 12 \\
\hline $2 D L 5$ & 7 & 0.63 & 6 & 0.48 & 6 & 0.51 & 3 & 0.53 & 6 & 0.73 & 10 \\
\hline $2 D S 1$ & 1 & 0.42 & 1 & 0.33 & 1 & 0.31 & 1 & 0.4 & 2 & 0.43 & 2 \\
\hline $2 D S 2$ & 1 & 0.36 & 1 & 0.44 & 2 & 0.46 & 1 & 0.73 & 1 & 0.48 & 2 \\
\hline $2 D S 3 / 5$ & 3 & 0.64 & 3 & 0.60 & 4 & 0.57 & 3 & 0.53 & 5 & 0.70 & 7 \\
\hline $2 D S 4$ & 5 & 0.79 & 5 & 0.62 & 5 & 0.80 & 5 & 0.8 & 6 & 0.76 & 6 \\
\hline $3 D L 1 / S 1$ & 10 & 0.79 & 15 & 0.83 & 14 & 0.86 & 9 & 0.93 & 15 & 0.85 & 19 \\
\hline $3 D L 2$ & 10 & 0.79 & 16 & 1.00 & 17 & 0.87 & 9 & 0.93 & 17 & 0.81 & 22 \\
\hline $3 D L 3$ & 20 & 0.94 & 26 & 0.96 & 26 & 0.97 & 15 & 0.93 & 39 & 0.99 & 44 \\
\hline
\end{tabular}

B

\begin{tabular}{|c|c|c|c|c|c|}
\hline $\begin{array}{c}\text { KIR } \\
\text { gene }\end{array}$ & $\begin{array}{c}\text { Closest } \\
\text { allele }\end{array}$ & $\begin{array}{c}\text { Nucleotide } \\
\text { change }\end{array}$ & $\begin{array}{l}\text { Coding } \\
\text { change }\end{array}$ & Domain & $\mathrm{N}$ \\
\hline \multirow[t]{2}{*}{$2 D L 1$} & *00201 & $\mathrm{G} 331 \mathrm{~T} \dagger$ & V $111 \mathrm{~L}$ & D0 & 1 \\
\hline & ${ }^{*} 00302$ & $\mathrm{G} 421 \mathrm{~A} \dagger$ & $\mathrm{A} 141 \mathrm{~T}$ & D1 & 2 \\
\hline \multirow[t]{2}{*}{$2 D L 4$} & *00801 & $G 568 A \dagger$ & G $190 \mathrm{R}$ & D2 & 2 \\
\hline & ${ }^{*} 00801$ & C $883 \mathrm{~A}$ & P 295 T & Cyt & 1 \\
\hline $3 D L 3$ & ${ }^{*} 01402$ & $\mathrm{G} 102 \mathrm{~A} \uparrow$ & W $34 \mathrm{X}$ & D0 & 1 \\
\hline $2 D S 4$ & ${ }^{*} 003$ & $\mathrm{~A} 110 \mathrm{C}+$ & $\mathrm{H} 37 \mathrm{P}$ & D1 & 2 \\
\hline $2 D S 5$ & ${ }^{*} 00201$ & $\mathrm{C} 252 \mathrm{~T}+$ & syn & Do & 1 \\
\hline \multirow[t]{2}{*}{$3 D S 1$} & *01301 & G 775 C & G $259 \mathrm{R}$ & D2 & 1 \\
\hline & ${ }^{*} 01301$ & T $1160 \mathrm{C}$ & $\mathrm{F} 387 \mathrm{~L}$ & Cyt & 2 \\
\hline \multirow[t]{3}{*}{$2 D P 1$} & ${ }^{*} 00301$ & $\mathrm{C} 702 \mathrm{~A} \dagger$ & - & - & \\
\hline & & C $703 \mathrm{G} \dagger$ & - & - & 2 \\
\hline & ${ }^{*} 00201$ & C $1107 \mathrm{~T}$ & - & - & 1 \\
\hline
\end{tabular}

FIGURE 2 | High KIR diversity and allele discovery in Iranians. (A) Shows the numbers of KIR alleles (K) and the heterozygosity (H) in each of the five Iranian populations. The total number observed is shown at the right. Gene absence is not included as an allele. (B) Shows the novel KIR alleles identified in this study. Columns from left to right are: the KIR gene, the closest known allele, the nucleotide change compared to the closest allele, the amino acid substitution caused by the nucleotide change, domain affected by the amino acid substitution (LP, leader peptide; DO-D1, Ig-like domains; TM, transmembrane domain) and the number observed. ${ }^{\dagger}$-indicates identical allele observed by Wagner et al. (47).

haplotypes can therefore provide the maximum number of activating KIR. The most frequent KIR-A haplotype encodes four inhibitory receptors specific for polymorphic HLA class I and carries KIR2DS4*003, which is not-expressed because of a $22 \mathrm{bp}$ deletion in exon 5 (11). Indeed, the frequency of the KIR2DS4 $22 b p$-del variant in Iranians is 0.62 , more than four times higher than the frequency of the full-length variant (Figure 3E). Consequently, almost all KIR-A haplotypes in Iranians encode four functional inhibitory receptors and no activating receptor specific for polymorphic HLA class I.
A characteristic of the KIR locus is the occurrence of largescale duplication or deletion events that encompass complete genes, which synergizes with allele variation to enhance KIR functional diversity $(45,49,50)$. In the Iranian cohort, we identified seven KIR haplotypes having large deletions and eight with duplications (Figure 4). One of these haplotypes (number 1 in Figure 4) was not observed previously and is similar to the most frequent $K I R-B$ haplotype in Iran, with the difference being that it lacks KIR2DS1. This haplotype could have been formed by homologous or looping out recombination (50). The remaining 
A

\begin{tabular}{ccc}
\multicolumn{3}{c}{ Number (Distinct) } \\
KIR haplotypes & A & B \\
\hline Centromeric & 112 & 59 \\
Telomeric & 66 & 34
\end{tabular}

B

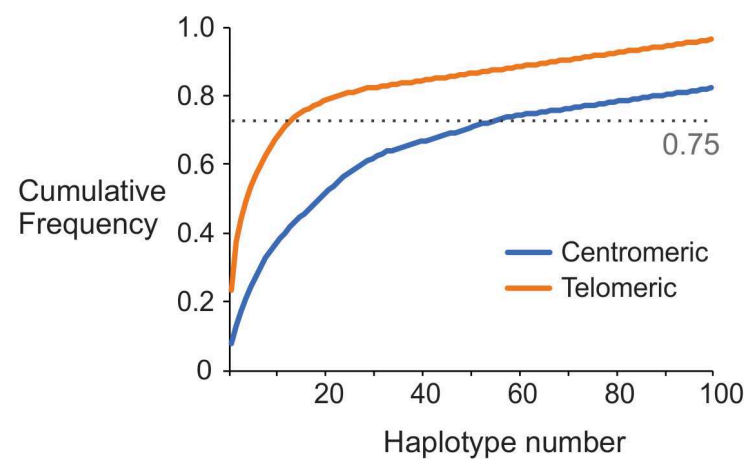

\begin{tabular}{|c|c|c|c|c|c|c|c|c|c|}
\hline \multirow[t]{2}{*}{ C } & \multicolumn{7}{|c|}{ Centromeric KIR Haplotypes } & \multirow[b]{2}{*}{$\mathrm{N}$} & \multirow[b]{2}{*}{ Freq. } \\
\hline & $3 D L 3$ & $2 D S 2$ & $2 D L 2 / 3$ & $2 D L 5$ & $2 D S 3 / 5$ & $2 D P 1$ & $2 D L 1$ & & \\
\hline 1 & ${ }^{*} 00301$ & ${ }^{*} 00101$ & $2 * 00101$ & $B * 00201$ & $3 * 00103$ & ${ }^{*} 00102$ & ${ }^{*} 00401$ & 40 & 0.166 \\
\hline 2 & ${ }^{\star} 00101$ & & $3^{*} 00101$ & & & ${ }^{*} 00201$ & *00302 & 25 & 0.104 \\
\hline 3 & ${ }^{*} 00901$ & & $3^{*} 00101$ & & & ${ }^{*} 00201$ & ${ }^{*} 00302$ & 22 & 0.091 \\
\hline 4 & ${ }^{*} 00902$ & & $3^{*} 00101$ & & & ${ }^{*} 00201$ & ${ }^{*} 00302$ & 17 & 0.071 \\
\hline 5 & ${ }^{*} 01501$ & & $3^{*} 00101$ & & & ${ }^{*} 00201$ & ${ }^{*} 00302$ & 17 & 0.071 \\
\hline 6 & ${ }^{*} 01101$ & & $3^{*} 00101$ & & & ${ }^{*} 005$ & ${ }^{*} 00302$ & 15 & 0.062 \\
\hline 7 & ${ }^{*} 007$ & ${ }^{*} 00101$ & $2 * 00301$ & & & & & 13 & 0.054 \\
\hline 8 & ${ }^{*} 02701$ & & $3 * 00501$ & & & ${ }^{*} 016$ & ${ }^{*} 001$ & 13 & 0.054 \\
\hline
\end{tabular}

\begin{tabular}{|c|c|c|c|c|c|c|c|c|c|}
\hline \multirow[t]{2}{*}{ D } & \multicolumn{7}{|c|}{ Telomeric KIR Haplotypes } & \multirow[b]{2}{*}{$\mathrm{N}$} & \multirow[b]{2}{*}{ Freq. } \\
\hline & $2 D L 4$ & $3 D L 1 / S 1$ & $2 D L 5 A$ & $2 D S 3 / 5$ & $2 D S 4$ & $2 D S 1$ & $3 D L 2$ & & \\
\hline 1 & ${ }^{*} 00801$ & ${ }^{*} 00101$ & & & ${ }^{*} 003$ & & ${ }^{*} 00101$ & 116 & 0.481 \\
\hline 2 & ${ }^{*} 00501$ & $S 1 * 01301$ & $A^{*} 00101$ & $S 5^{\star} 00201$ & & ${ }^{*} 00201$ & ${ }^{*} 00701$ & 71 & 0.295 \\
\hline 3 & ${ }^{*} 00103$ & ${ }^{*} 008$ & & & ${ }^{*} 003$ & & ${ }^{*} 00901$ & 39 & 0.162 \\
\hline 4 & ${ }^{*} 00102$ & ${ }^{*} 002$ & & & ${ }^{*} 00101$ & & ${ }^{*} 00201$ & 26 & 0.108 \\
\hline 5 & ${ }^{*} 00602$ & ${ }^{*} 00701$ & & & ${ }^{*} 004$ & & ${ }^{*} 008$ & 23 & 0.095 \\
\hline 6 & ${ }^{*} 011$ & ${ }^{*} 00501$ & & & ${ }^{*} 010$ & & ${ }^{*} 010$ & 17 & 0.071 \\
\hline 7 & ${ }^{*} 00102$ & ${ }^{*} 01502$ & & & ${ }^{*} 00101$ & & ${ }^{*} 00201$ & 15 & 0.062 \\
\hline 8 & ${ }^{*} 00802$ & ${ }^{*} 00401$ & & & ${ }^{*} 006$ & & ${ }^{*} 00501$ & 14 & 0.058 \\
\hline 9 & ${ }^{*} 00501$ & $S 1^{\star} 01301$ & $A^{*} 00501$ & $S 3^{*} 00201$ & & ${ }^{\star} 00201$ & ${ }^{*} 00701$ & 13 & 0.054 \\
\hline 10 & ${ }^{*} 00802$ & ${ }^{*} 00402$ & & & ${ }^{*} 006$ & & ${ }^{*} 00501$ & 12 & 0.050 \\
\hline
\end{tabular}

E

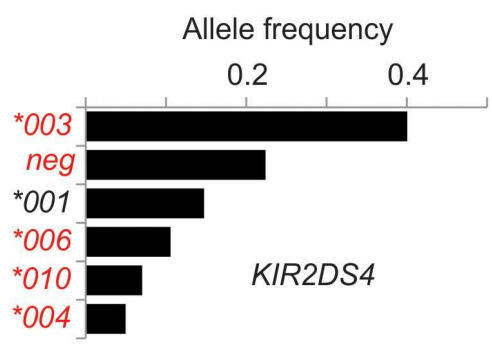

Allele frequency
0.1
0.2
0.3

FIGURE 3 | Centromeric KIR are more diverse than telomeric KIR in Iranians. (A) Shows the number of distinct haplotypes observed in the centromeric and telomeric KIR regions. (B) Shows the cumulative frequency of haplotypes observed in the centromeric and telomeric KIR regions. (C,D) Shows the allele composition of all (C) centromeric, and (D) telomeric KIR haplotypes identified in more than ten individuals in the combined Iranian population. KIR A haplotypes are shaded pink and KIR $B$ haplotypes are blue. Empty boxes indicate gene absence. At the right is shown number observed and the frequency in the combined Iranian population $(N=241)$. All the observed haplotypes are given in Supplementary Material (E). Shown are the frequencies of KIR2DL4 and KIR2DS4 alleles in the combined Iranian population. Red text indicates alleles not expressed at cell surface. The allele frequencies for all KIR genes in each of the five populations are given in Supplementary Material. 


\begin{tabular}{|c|c|c|c|c|c|c|c|c|c|c|c|c|c|c|c|c|c|}
\hline & \multicolumn{17}{|c|}{ KIR gene } \\
\hline & $3 D L 3$ & $2 D S 2$ & $2 D L 2 / 3$ & $2 D L 5$ & $2 D S 3 / 5$ & $2 D P 1$ & $2 D L 1$ & $20 L 4$ & $3 D L 1 / S 1$ & $2 D L 4$ & $3 D L 1 / S 1$ & $2 D L 5$ & $2 D S 3 / 5$ & $2 D S 1$ & $20 S 4$ & $3 D L 2$ & $\mathrm{~N}$ \\
\hline 1 & ${ }^{*} 01309$ & & $3 * 00201$ & & & ${ }^{*} 00301$ & ${ }^{*} 00302$ & & & $* 00501$ & $S 1 * 01301$ & $A^{*} 00101$ & $5 * 00201$ & & & $* 00701$ & 1 \\
\hline 2 & $* 036$ & ${ }^{*} 001$ & $2 * 00101$ & $B * 00801$ & $5 * 00201$ & & & & & & & & & ${ }^{*} 00201$ & & $* 00701$ & 1 \\
\hline 3 & ${ }^{*} 00301$ & ${ }^{*} 001$ & $2 * 00101$ & $B^{*} 00801$ & $5 * 00201$ & & & & & & & & & ${ }^{*} 00201$ & & $* 00701$ & 2 \\
\hline 4 & ${ }^{*} 00301$ & $* 001$ & $2 * 00301$ & $A^{*} 00102$ & $5 * 00201$ & & & & & & & & & ${ }^{*} 00201$ & & $* 00701$ & 1 \\
\hline 5 & ${ }^{*} 00301$ & ${ }^{*} 001$ & $2 * 00101$ & $B * 00201$ & $3 * 00201$ & & & & & & & & & $*_{00201}$ & & $*^{*} 019$ & 1 \\
\hline 6 & ${ }^{*} 00202$ & ${ }^{*} 001$ & $2 * 00301$ & $B^{*} 00201$ & $3 * 00201$ & & & & & & & & & ${ }^{*} 00201$ & & ${ }^{*} 00701$ & 1 \\
\hline 7 & ${ }^{*} 00301$ & ${ }^{*} 001$ & $2 * 00101$ & & & & & & & & & & & & & ${ }^{*} 00701$ & 1 \\
\hline 8 & ${ }^{*} 00301$ & ${ }^{*} 001$ & $2 * 00101$ & $A^{*} 00501$ & $3^{*} 00103$ & ${ }^{*} 00102$ & ${ }^{*} 00401$ & ${ }^{*} 00501$ & $S 1^{*} 01301$ & ${ }^{*} 00801$ & $\angle 1 * 00101$ & & & & ${ }^{*} 00101$ & ${ }^{*} 00202$ & 1 \\
\hline 9 & ${ }^{*} 00202$ & & $3 * 00101$ & & & ${ }^{*} 005$ & ${ }^{*} 00302$ & ${ }^{*} 00501$ & $51 * 01301$ & $* 00103$ & $\angle 1 * 008$ & & & & $* 003$ & $* 00701$ & 1 \\
\hline 10 & *00901 & & $3 * 00101$ & & & $* 00201$ & ${ }^{*} 00302$ & ${ }^{*} 00501$ & $S 1 * 01301$ & *00801 & $\angle 1 * 00101$ & & & & $* 003$ & $* 00101$ & 1 \\
\hline 11 & ${ }^{*} 00202$ & & $3^{*} 00101$ & & & ${ }^{*} 00201$ & ${ }^{*} 00302$ & ${ }^{*} 00501$ & $S 1^{*} 01301$ & *00102 & $\angle 1 * 01502$ & & & & ${ }^{*} 00101$ & $* 00201$ & 1 \\
\hline 12 & ${ }^{*} 00301$ & $* 001$ & $2 * 00101$ & $B^{*} 00201$ & $3 * 00201$ & ${ }^{*} 00102$ & $* 00401$ & ${ }^{*} 00801$ & $\angle 1 * 00101$ & $* 00501$ & $S 1 * 01301$ & $A * 00501$ & $5 * 00201$ & & $* 003$ & $* 00701$ & 1 \\
\hline 13 & ${ }^{*} 041$ & & $3 * 00501$ & & & ${ }^{*} 00102$ & $* 00401$ & ${ }^{*} 00801$ & $\angle 1 * 00101$ & ${ }^{*} 00501$ & $S 1 * 01301$ & $A * 00501$ & $3 * 00103$ & & ${ }^{*} 003$ & ${ }^{*} 00901$ & 1 \\
\hline 14 & ${ }^{*} 00101$ & ${ }^{*} 001$ & $2 * 00101$ & $B * 00201$ & $3 * 00103$ & ${ }^{*} 00102$ & $* 00401$ & ${ }^{*} 00801$ & $\angle 1 * 00101$ & ${ }^{*} 00501$ & $S 1 * 01301$ & $A^{*} 00501$ & $3 * 00103$ & & ${ }^{*} 003$ & $*^{*} 00101$ & 1 \\
\hline 15 & ${ }^{*} 00301$ & ${ }^{*} 001$ & $2 * 00101$ & & & ${ }^{*} 00301$ & ${ }^{*} 010$ & ${ }^{*} 00801$ & $\angle 1 * 00101$ & ${ }^{*} 00501$ & $51 * 01301$ & $A * 00501$ & $3 * 003 N$ & $* 00201$ & ${ }^{*} 00101$ & $* 00701$ & 1 \\
\hline
\end{tabular}

Deleted segment

Duplicated segment

FIGURE 4 | Rare structural variants of KIR haplotypes in Iranians. Shown are Iranian KIR haplotypes affected by a copy number variation. Gray and purple boxes highlight deleted or duplicated segments, respectively. " $N$ " indicates the number observed.

deletion haplotypes are similar to those observed worldwide including Africans, and the duplication haplotypes similar to those observed outside of Africa (45).

The interaction of HLA class I with inhibitory KIR contributes to NK cell education $(51,52)$. We analyzed the distribution of alleles for the four inhibitory KIR that are specific for HLA class I in Iranians and compared them with six other populations that represent the breadth of human genetic diversity (Figure 5). This analysis showed that in Iranians, Europeans, West Africans, and Japanese the most frequent KIR2DL1 and KIR2DL2/3 alleles are $2 D L 1^{*} 003$ and $2 D L 3^{*} 001$, respectively. The two populations that differ are relatively small indigenous populations (Figures $5 \mathbf{A}, \mathbf{B}$ ). By contrast, the KIR3DL1/S1 and KIR3DL2 alleles most frequent in Iranians are usually not the same as those most frequent in other populations (Figures $\mathbf{5 C , D}$ ). This shows there is a greater worldwide divergence of KIR specific for HLA-A and -B than of KIR specific for HLA-C. Of particular note, Iranian populations have the highest frequency of $3 D L 1^{*} 001(0.29)$ compared to the other six populations as well as to all other populations analyzed to date (53). Allele frequencies of the four inhibitory KIR specific for HLA class I are similar across the Iranian populations analyzed (Figures 5E-H). The one exception is the Baloch who have a low frequency of KIR3DL $1^{*} 004$, as well as KIR3DL2*003 and $* 005$, which are in strong linkage disequilibrium with $3 D L 1^{*} 004(28,44)$ (Supplementary Material C). The Baloch have one tenth the frequency of $3 D L 1^{*} 004$ (0.015) than Kurd $\left[0.114, \chi^{2} p=0.006 ; \mathrm{pc}=0.06(\mathrm{~ns})\right]$, Lorestan $\left[0.109, \chi^{2} p=\right.$ $0.006 ; \mathrm{pc}=0.06(\mathrm{~ns})]$ and Yasuj [0.129, $\chi 2 \mathrm{p}=0.003 ; \mathrm{pc}=0.03]$. KIR3DL1*004 is retained in the cytoplasm and unable to bind HLA-Bw4+ HLA-A or -B on target cells (54).

We examined the compound genotypes of KIR and HLA class $I$, to determine the potential number of interactions between HLA class I ligands and inhibitory KIR. We observed a consistent mean of four viable interactions per individual of HLA-C with inhibitory KIR across the five Iranian populations (Figure 6A). This number is similar to the mean of 3.6 observed in Europeans (28). Although we observed no significant difference in the potential interactions of KIR3DL1 with HLA-A, the Baloch and Lordegan have more interactions of KIR3DL1 with HLA-B than the other three Iranian populations (Figures 6B,C). Despite the small numbers of individuals in these groups, the differences are statistically significant (Mann-Whitney $U$-test; $p<0.013$ ). Contributing to these differences is the high frequency of HLA$B^{*} 51$ in the Baloch (0.29; Supplementary Material D). This frequency is similar to the 0.28 observed in the Lordegan and considered the highest worldwide (34).

\section{DISCUSSION}

This study applied high-throughput, next-generation sequencing to define KIR polymorphism at high resolution in five Iranian populations. These comprise the Kurd and Lur populations from the Zagros Mountains in the west of Iran and the Baloch from the south-east. The Lur comprised three subpopulations; the Lorestan, Lordegan, and Yasuj. HLA class I allele distributions for four of these populations were reported previously (34) whereas those for the Baloch are described here. When we compared the KIR allele frequencies of Iranians to those representing African, Asian, European, Oceanian, and South American populations, we found that the Iranian groups we studied are particularly similar to Europeans. This finding is consistent with ancient DNA analysis, which revealed that Iranians and Europeans both originate from an Indo-Europeans steppe ancestor population (55).

Despite their overall similarity, the Iranians we studied differ from Europeans in their frequencies of KIR $3 D L 1^{*} 001$, a highexpressing inhibitory receptor specific for the Bw4 epitope of 


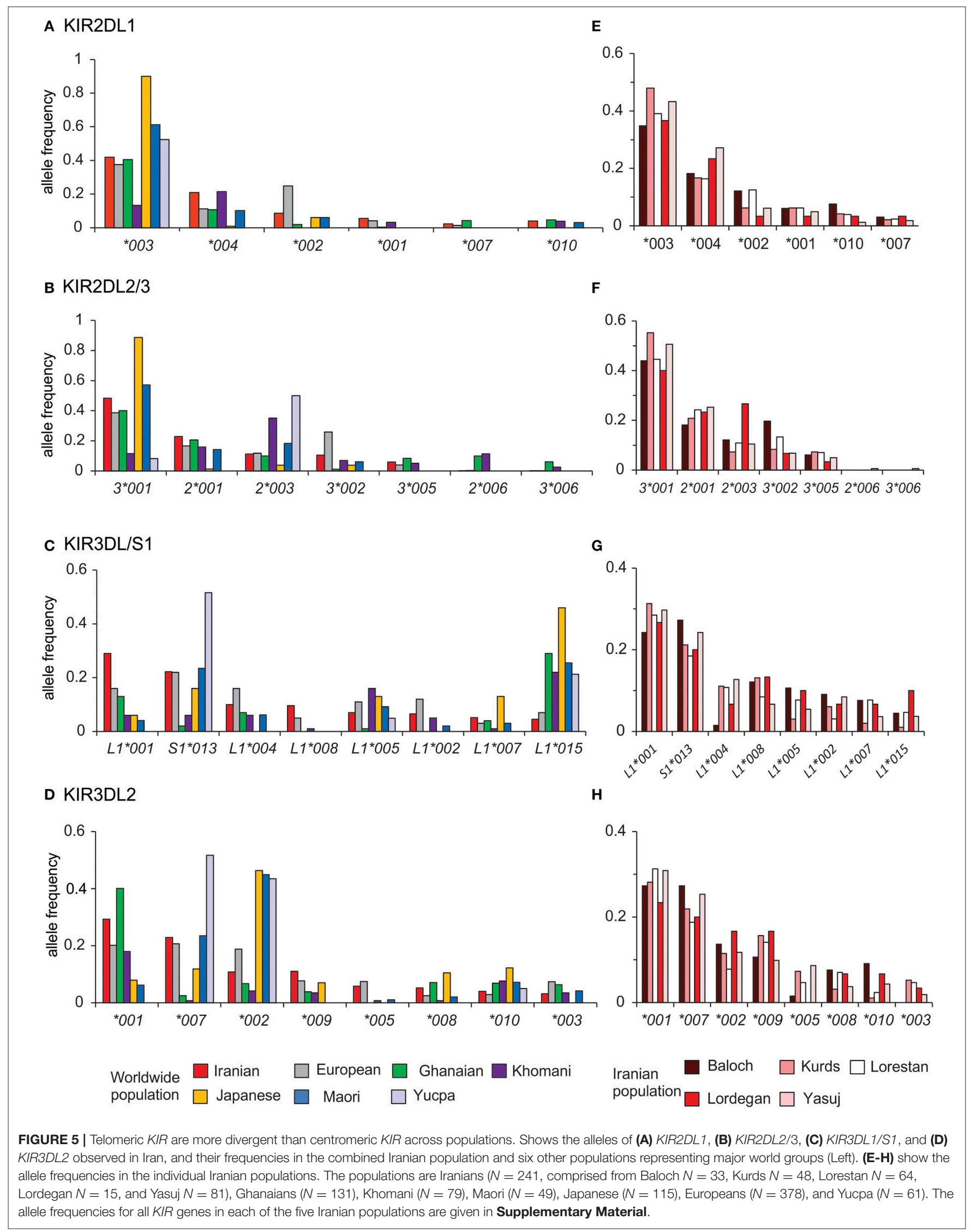




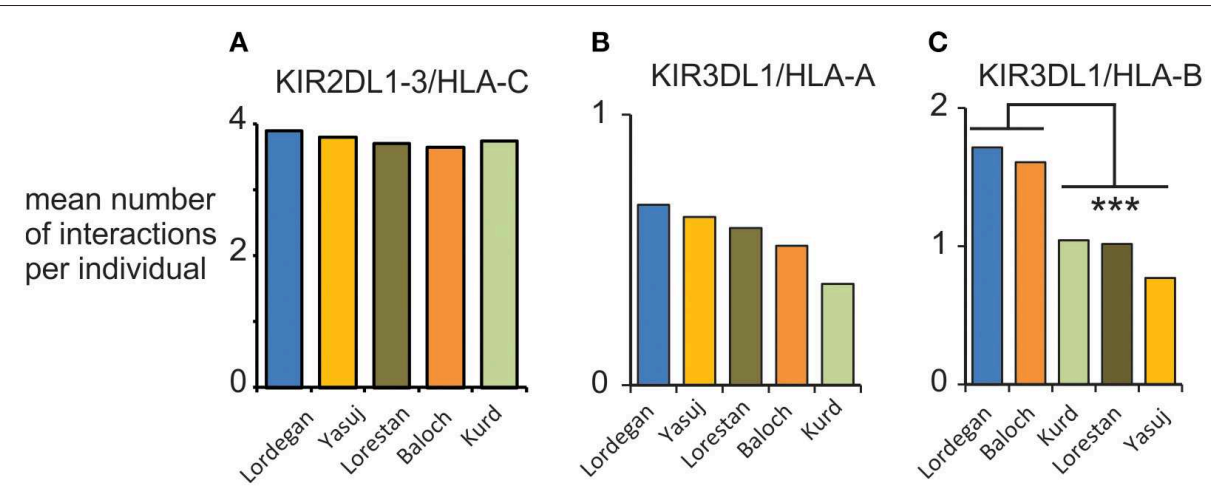

FIGURE 6 | Interactions between KIR and HLA class I in five Iranian populations. (A) Shows the mean total number of viable interactions per individual of inhibitory KIR and HLA-C. (B) Shows the mean total number of viable interactions per individual of KIR3DL1 and HLA-A. (C) Shows the mean total number of viable interactions per individual of KIR3DL1 and HLA-B. ${ }^{\star \star \star} p<0.013$, obtained from a two-tailed Mann-Whitney $U$-test.

subsets of HLA-A and -B allotypes. Iranians have KIR3DL1*001 frequencies that are twice those in Europeans and are the highest worldwide. Iran has the highest frequency of HLA$B^{*} 51$ in the world (34), and this is also the case for the Baloch. HLA-B*51 has the Bw4 epitope and thus educates ${\mathrm{KIR} 3 \mathrm{DL} 1^{+}}^{+} \mathrm{NK}$ cells to detect any loss in $\mathrm{Bw} 4^{+}$HLA-A or B expression $(35,56,57)$. HLA-B* 51 is associated with Behçet disease, a chronic, multi-system autoimmune condition that has substantially higher incidence in Iran $(80 / 100,000)$ than Europe $(<1 / 100,000)(58,59)$. We recently showed that high-expressing allotypes of KIR3DL1, including 3DL1*001, can protect from Behçet disease (60). It is unlikely that KIR3DL1*001 and HLA$\mathrm{B}^{*} 51$ rose to high frequency in Iran to protect specifically from an autoimmune disease, but this combination of HLA and KIR could also protect against specific infectious diseases (7). Examples include tuberculosis and hepatitis, which are both prevalent in Balochistan (61-63). Amongst Iranians, the Baloch and Lordegan have the highest number of viable interactions between KIR3DL1 and Bw4 $4^{+}$HLA. Contributing to this high occurrence in the Baloch, are high frequencies of KIR3DL1*001 and HLA-B* 51 and a low frequency of KIR3DL1*004. That both the KIR3DL2 alleles linked to KIR3DL1*004 are also reduced in frequency suggests that KIR3DL1*004 has been specifically targeted by negative selection in the Baloch, rather than another $K I R$ allele in linkage disequilibrium with KIR3DL1*004.

KIR- $A$ and $-B$ haplotypes are present in all human populations, where they are maintained by balancing selection, likely because KIR-A haplotypes favor infection control, particularly viral infections, and KIR-B haplotypes favor successful fetal implantation (1, 16). Accordingly, KIR-A haplotypes express all possible inhibitory receptors specific for HLA class I, whereas KIR-B haplotypes express fewer inhibitory receptors but more activating receptors. Thus, whereas the inhibitory KIR help prime NK cells to be able to be responsive to HLA class I loss during infection, the activating KIR can both promote fetal trophoblast invasion and recognize specific pathogen-derived peptides to control certain infections $(64,65)$. In Iranian populations the differences between the KIR-A and $K I R-B$ haplotypes is extreme. The common KIR-A haplotypes express no activating KIR, due to the high frequency of the truncated KIR2DS4 variant, and the common KIR-B haplotypes provide the maximum number of activating receptors. In this regard, the KIR-B haplotypes differ considerably from those of Africans and were likely obtained since the out of Africa migration, through adaptive introgression with ancient humans (66).

In summary, we describe the KIR locus at allelic resolution in Iranian populations and place it in the context of the HLA ligands recognized by KIR. Iran is a culturally diverse country and the ethnic groups we have studied comprise $\sim 15 \%$ of the population (67). Because substantial KIR gene content diversity is observed across Iran (68-71), it will be of interest in future studies to compare our results with other Iranian populations including Persians and Azeris. The allele and haplotype distributions described here will provide a baseline for future studies of disease association and transplantation matching in this important region of the world.

\section{DATA AVAILABILITY STATEMENT}

All relevant data are included in the article/Supplementary Material. Other raw data supporting the conclusions of this article will be made available by the authors, without undue reservation, to any qualified researcher.

\section{ETHICS STATEMENT}

The studies involving human participants were reviewed and approved by the Medical Research Ethics Committee of Shiraz University of Medical Sciences. The patients/participants provided their written informed consent to participate in this study.

\section{AUTHOR CONTRIBUTIONS}

PP, EA, AG, and PN conceived and designed experiments. EA, NN-G, and ST performed lab experiments. CA, PN, JAT, LG, NN-G, and ST analyzed data. AG, PP, WM, JH, JT, and LM provided materials. CA, PN, and PP wrote the paper. All authors approved the final submitted version. 


\section{FUNDING}

This work was supported by National Institutes of Health Grants R01 AI017892 and U01 AI090905. The project received funding from the European Research Council (ERC) under the European Union's Horizon 2020 research and innovation program (grant agreement No. 695551).

\section{ACKNOWLEDGMENTS}

We thank all of the participants of this study for their generous donation of DNA to facilitate genetic research. CA is recipient of a post-doctoral fellowship from the Fondazione Umberto Veronesi.

\section{REFERENCES}

1. Parham P, Moffett A. Variable NK cell receptors and their MHC class I ligands in immunity, reproduction and human evolution. Nat Rev Immunol. (2013) 13:133-44. doi: 10.1038/nri3370

2. Vance RE, Eichberg MJ, Portnoy DA, Raule, D. Listening to each other: infectious disease and cancer immunology. Sci Immunol. (2017) 2:eaai9339. doi: 10.1126/sciimmunol.aai9339

3. Long EO, Kim HS, Liu D, Peterson ME, Rajagopalan S. Controlling natural killer cell responses: integration of signals for activation and inhibition. Annu Rev Immunol. (2013) 31:227-58. doi: 10.1146/annurev-immunol-020711-075005

4. Lam VC, Lanier LL. NK cells in host responses to viral infections. Curr Opin Immunol. (2017) 44:43-51. doi: 10.1016/j.coi.2016.11.003

5. Stewart CA, Vivier E, Colonna M. Strategies of natural killer cell recognition and signaling. Curr Top Microbiol Immunol. (2006) 298:1-21. doi: 10.1007/3-540-27743-9_1

6. Moretta L, Pietra G, Montaldo E, Vacca P, Pende D, Falco M, et al. Human NK cells: from surface receptors to the therapy of leukemias and solid tumors. Front Immunol. (2014) 5:87. doi: 10.3389/fimmu.2014.00087

7. Bashirova AA, Martin MP, McVicar, DW, Carrington M. The killer immunoglobulin-like receptor gene cluster: tuning the genome for defense. Annu Rev Genomics Hum Genet. (2006) 7:277-300. doi: 10.1146/annurev.genom.7.080505.115726

8. Locatelli F, Pende D, Falco M, Della Chiesa M, Moretta A, Moretta L. NK cells mediate a crucial graft-versus-leukemia effect in haploidenticalHSCT to cure high-risk acute leukemia. Trends Immunol. (2018) 39:577-90. doi: 10.1016/j.it.2018.04.009

9. Wilson MJ, Torkar M, Haude A, Milne S, Jones T, Sheer D, et al. Plasticity in the organization and sequences of human KIR/ILT gene families. Proc Natl Acad Sci USA. (2000) 97:4778-83. doi: 10.1073/pnas.080588597

10. Uhrberg M, Valiante NM, Shum BP, Shilling H, Lienert-Weidenbach K, Corliss B, et al. Human diversity in killer cell inhibitory receptor genes. Immunity. (1997) 7:753-63. doi: 10.1016/S1074-7613(00)80394-5

11. Hsu KC, Liu XR, Selvakumar A, Mickelson E, O’Reilly R, Dupont B. Killer Ig-like receptor haplotype analysis by gene content: evidence for genomic diversity with a minimum of six basic framework haplotypes, each with multiple subsets. J Immunol. (2002) 169:5118-29. doi: 10.4049/jimmunol.169.9.5118

12. Marsh SG, Parham P, Dupont B, Geraghty DE, Trowsdale J, Middleton D. Killer-cell immunoglobulin-like receptor (KIR) nomenclature report, 2002. Tissue Antigens. (2003) 62:79-86. doi: 10.1034/j.1399-0039.2003.00072.x

13. Kikuchi-Maki A, Catina TL, Campbell KS. Cutting edge: KIR2DL4 transduces signals into human NK cells through association with the Fc receptor gamma protein. J Immunol. (2005) 174:3859-63. doi: 10.4049/jimmunol.174.7.3859

14. Miah SM, Hughes TL, Campbell KS. KIR2DL4 differentially signals downstream functions in human NK cells through distinct structural modules. J Immunol. (2008) 180:2922-32. doi: 10.4049/jimmunol.180.5.2922

\section{SUPPLEMENTARY MATERIAL}

The Supplementary Material for this article can be found online at: https://www.frontiersin.org/articles/10.3389/fimmu. 2020.00556/full\#supplementary-material

Supplementary Material (Spreadsheet) | (A) Shown are the allele frequencies for the 13 KIR genes in five Iranian populations, and the combined frequency is shown at the right. (B) Shown are the centromeric KIR haplotypes identified in five Iranian populations. The combined frequency is shown at the right. KIR A haplotypes are shaded in red, KIR B haplotypes are shaded in blue. (C) Shown are the telomeric KIR haplotypes identified in five Iranian populations. The combined frequency is shown at the right. KIR A haplotypes are shaded in red, $K I R B$ haplotypes are shaded in blue. Yellow shading indicates novel KIR alleles identified in this study, which are described in Figure 2. (D) Shows the HLA class I allele frequencies observed in the Baloch population.

15. Rajagopalan S, Long EO. KIR2DL4 (CD158d): an activation receptor for HLA-G. Front Immunol. (2012) 3:258. doi: 10.3389/fimmu.2012.00258

16. Guethlein LA, Norman PJ, Hilton HH, Parham P. Co-evolution of MHC class I and variable NK cell receptors in placental mammals. Immunol Rev. (2015) 267:259-82. doi: 10.1111/imr.12326

17. Pyo CW, Guethlein LA, Vu Q, Wang R, Abi-Rached L, Norman PJ, et al. Different patterns of evolution in the centromeric and telomeric regions of group A and B haplotypes of the human killer cell Ig-like receptor locus. PLoS ONE. (2010) 5:e15115. doi: 10.1371/journal.pone.0015115

18. Cooley S, Weisdorf DJ, Guethlein LA, Klein J, Wang T, Le CT, et al. Donor selection for natural killer cell receptor genes leads to superior survival after unrelated transplantation for acute myelogenous leukemia. Blood. (2010) 116:2411-9. doi: 10.1182/blood-2010-05-283051

19. Oevermann L, Michaelis SU, Mezger M, Lang P, Toporski J, Bertaina A, et al. KIR B haplotype donors confer a reduced risk for relapse after haploidentical transplantation in children with all. Blood. (2014) 124:2744-7. doi: 10.1182/blood-2014-03-565069

20. Winter CC, Gumperz JE, Parham P, Long EO, Wagtmann N. Direct binding and functional transfer of NK cell inhibitory receptors reveal novel patterns of HLA-C allotype recognition. J Immunol. (1998) 161:571-7.

21. Pando MJ, Gardiner CM, Gleimer M, McQueen KL, Parham P. The protein made from a common allele of KIR3DL1 (3DL1*004) is poorly expressed at cell surfaces due to substitution at positions 86 in Ig domain $0182 \mathrm{in} \mathrm{Ig}$ domain 1. J Immunol. (2003) 171:6640-9. doi: 10.4049/jimmunol.171.12.6640

22. Moesta AK, Norman PJ, Yawata M, Yawata N, Gleimer M, Parham P. Synergistic polymorphism at two positions distal to the ligand-binding site makes KIR2DL2 a stronger receptor for HLA-C than KIR2DL3. J Immunol. (2008) 180:3969-79. doi: 10.4049/jimmunol.180.6.3969

23. Bari R, Bell T, Leung WH, Vong QP, Chan WK, Das Gupta N. Significant functional heterogeneity among KIR2DL1 alleles and a pivotal role of arginine 245. Blood. (2009) 114:5182-90. doi: 10.1182/blood-2009-07-231977

24. VandenBussche CJ, Mulrooney TJ, Frazier WR, Dakshanamurthy S, Hurley CK. Dramatically reduced surface expression of NK cell receptor KIR2DS3 is attributed to multiple residues throughout the molecule. Genes Immun. (2009) 10:162-73. doi: 10.1038/gene.2008.91

25. Hilton HG, Guethlein LA, Goyos A, Nemat-Gorgani N, Bushnell D, Norman PJ, et al. Polymorphic HLA-C receptors balance the functional characteristics of KIR haplotypes. J Immunol. (2015) 195:3160-70. doi: 10.4049/jimmunol.1501358

26. Gendzekhadze K, Norman PJ, Abi-Rached L, Graef T, Moesta A, Layrisse Z, et al. Co-evolution of KIR2DL3 with HLA-C in a human population retaining minimal essential diversity of KIR and HLA class I ligands. Proc Natl Acad Sci USA. (2009) 106:18692-7. doi: 10.1073/pnas.0906051106

27. Norman PJ, Hollenbach JA, Nemat-Gorgani N, Guethlein LA, Hilton HG, Pando MJ, et al. Co-evolution of human leukocyte antigen (HLA) class I ligands with killer-cell immunoglobulin-like receptors (KIR) in a genetically diverse population of sub-Saharan Africans. PLoS Genet. (2013) 9:e1003938. doi: 10.1371/journal.pgen.1003938 
28. Nemat-Gorgani N, Hilton HG, Henn BM, Lin M, Gignoux CR, Myrick JW, et al. Different selected mechanisms attenuated the inhibitory interaction of KIR2DL1 with $\mathrm{C} 2(+)$ HLA-C in two indigenous human populations in Southern Africa. J Immunol. (2018) 200:2640-55. doi: 10.4049/jimmunol.1701780

29. Nemat-Gorgani N, Guethlein LA, Henn BM, Norberg S, Chiaroni J, Sikora M, et al. Diversity of KIR, HLA class I, their interactions in seven populations of sub-Saharan Africans. J Immunol. (2019) 202:2636-47. doi: 10.4049/jimmunol.1801586

30. Middleton D, Meenagh A, Gourraud PA. KIR haplotype content at the allele level in 77 Northern Irish families. Immunogenetics. (2007) 59:145-58. doi: 10.1007/s00251-006-0181-7

31. Vierra-Green C, Roe D, Hou L, Hurley CK, Rajalingam R, Reed E, et al. Allele-level haplotype frequencies and pairwise linkage disequilibrium for 14 KIR loci in 506 European-American individuals. PLoS ONE. (2012) 7:e47491. doi: 10.1371/journal.pone.0047491

32. Yawata M, Yawata N, Draghi M, Little AM, Partheniou F, Parham P. Roles for HLA and KIR polymorphisms in natural killer cell repertoire selection and modulation of effector function. J Exp Med. (2006) 203:633-45. doi: 10.1084/jem.20051884

33. Nemat-Gorgani N, Edinur HA, Hollenbach JA, Traherne J, Dunn PP, Chambers GK, et al. KIR diversity in Maori and Polynesians: populations in which HLA-B is not a significant KIR ligand. Immunogenetics. (2014) 66:597-611. doi: 10.1007/s00251-014-0794-1

34. Ashouri E, Norman PJ, Guethlein LA, Han A, Nemat-Gorgani N, Norberg SJ, et al. HLA class I variation in Iranian Lur and Kurd populations: high haplotype and allotype diversity with an abundance of KIR ligands. HLA. (2016) 88:87-99. doi: 10.1111/tan.12852

35. Cella M, Longo A, Ferrara GB, Strominger JL, Colonna M. NK3-specific natural killer cells are selectively inhibited by Bw4-positive HLA alleles with isoleucine 80. J Exp Med. (1994) 180:1235-42. doi: 10.1084/jem.180.4.1235

36. Saunders PM, Pymm P, Pietra G, Hughes VA, Hitchen C, O'Connor GM, et al. Killer cell immunoglobulin-like receptor 3DL1 polymorphism defines distinct hierarchies of HLA class I recognition. J Exp Med. (2016) 213:791-807. doi: 10.1084 /jem.20152023

37. Norman PJ, Hollenbach JA, Nemat-Gorgani N, Marin WM, Norberg SJ, Ashouri E, et al. Defining KIR and HLA class I genotypes at highest resolution via high-throughput sequencing. Am J Hum Genet. (2016) 99:37591. doi: 10.1016/j.ajhg.2016.06.023

38. Langmead B, Salzberg S L. Fast gapped-read alignment with Bowtie 2. Nat Methods. (2012) 9:357-9. doi: 10.1038/nmeth.1923

39. Chevreux B, Pfisterer T, Drescher B, Driesel AJ, Muller W, Wetter T, et al. Using the miraEST assembler for reliable and automated mRNA transcript assembly and SNP detection in sequenced ESTs. Genome Res. (2004) 14:114759. doi: 10.1101/gr.1917404

40. Bonfield JK, Whitwham A. Gap5-editing the billion fragment sequence assembly. Bioinformatics. (2010) 26:1699-703. doi: 10.1093/bioinformatics/btq268

41. Thorvaldsdottir H, Robinson JT, Mesirov JP. Integrative genomics viewer (IGV): high-performance genomics data visualization and exploration. Brief Bioinformatics. (2013) 14:178-92. doi: 10.1093/bib/bbs017

42. Stephens M, Donnelly P. A comparison of bayesian methods for haplotype reconstruction from population genotype data. Am J Hum Genet. (2003) 73:1162-9. doi: 10.1086/379378

43. Cavalli-Sforza LL, Edwards AW. Phylogenetic analysis. models and estimation procedures. Am J Hum Genet. (1967) 19(3 Pt 1):233-57. doi: 10.2307/2406616

44. Misra MK, Augusto DG, Martin GM, Nemat-Gorgani N, Sauter J, Hofmann JA, et al. Report from the killer-cell immunoglobulin-like receptors (KIR) component of the 17th international hla and immunogenetics workshop. Hum Immunol. (2018) 79:825-33. doi: 10.1016/j.humimm.2018.10.003

45. Norman PJ, Abi-Rached L, Gendzekhadze K, Hammond JA, Moesta A, Sharma D, et al. Meiotic recombination generates rich diversity in NK cell receptor genes, alleles, and haplotypes. Genome Res. (2009) 19:757-69. doi: 10.1101/gr.085738.108

46. Hollenbach JA, Nocedal I, Ladner MB, Single RM, Trachtenberg EA. Killer cell immunoglobulin-like receptor (KIR) gene content variation in the HGDP-CEPH populations. Immunogenetics. (2012) 64:719-37. doi: 10.1007/s00251-012-0629-x
47. Wagner I, Schefzyk D, Pruschke J, Schofl G, Schone B, Gruber N, et al. Allele-level KIR genotyping of more than a million samples: workflow, algorithm, and observations. Front Immunol. (2018) 9:2843. doi: 10.3389/fimmu.2018.02843

48. Robinson J, Halliwell JA, Hayhurst JD, Flicek P, Parham P, Marsh SG, et al. The IPD and IMGT/HLA database: allele variant databases. Nucleic Acids Res. (2015) 43:D423-31. doi: 10.1093/nar/gku1161

49. Martin MP, Bashirova A, Traherne J, Trowsdale J, Carrington M. Cutting edge: expansion of the KIR locus by unequal crossing over. J Immunol. (2003) 171:2192-5. doi: 10.4049/jimmunol.171.5.2192

50. Traherne JA, Martin M, Ward R, Ohashi M, Pellett F, Gladman D, et al. Mechanisms of copy number variation and hybrid gene formation in the KIR immune gene complex. Hum Mol Genet. (2010) 19:737-51. doi: $10.1093 / \mathrm{hmg} / \mathrm{ddp} 538$

51. Anfossi N, Andre P, Guia S, Falk CS, Roetynck S, Stewart CA, et al. Human NK cell education by inhibitory receptors for MHC class I. Immunity. (2006) 25:331-42. doi: 10.1016/j.immuni.2006.06.013

52. Goodridge JP, Jacobs B, Saetersmoen ML, Clement D, Hammer Q, Clancy $\mathrm{T}$, et al. Remodeling of secretory lysosomes during education tunes functional potential in NK cells. Nat Commun. (2019) 10:514. doi: 10.1038/s41467-019-08384-x

53. Norman PJ, Abi-Rached L, Gendzekhadze K, Korbel D, Gleimer M, Rowley $\mathrm{D}$, et al. Unusual selection on the KIR3DL1/S1 natural killer cell receptor in Africans. Nat Genet. (2007) 39:1092-9. doi: 10.1038/ng2111

54. Taner SB, Pando MJ, Roberts A, Schellekens J, Marsh S, Malmberg KJ, et al. Interactions of $\mathrm{NK}$ cell receptor KIR3DL1*004 with chaperones and conformation-specific antibody reveal a functional folded state as well as predominant intracellular retention. J Immunol. (2011) 186:62-72. doi: 10.4049/jimmunol.0903657

55. Broushaki F, Thomas MG, Link V, Lopez S, van Dorp L, Kirsanow K, et al. Early neolithic genomes from the eastern Fertile Crescent. Science. (2016) 353:499-503. doi: 10.1126/science.aaf7943

56. Gumperz JE, Litwin V, Phillips JH, Lanier LL, Parham P. The Bw4 public epitope of HLA-B molecules confers reactivity with natural killer cell clones that express NKB1, a putative HLA receptor. J Exp Med. (1995) 181:1133-44. doi: $10.1084 /$ jem.181.3.1133

57. Carr WH, Pando MJ, Parham P. KIR3DL1 polymorphisms that affect NK cell inhibition by HLA-Bw4 ligand. J Immunol. (2005) 175:5222-9. doi: 10.4049/jimmunol.175.8.5222

58. Ohno S, Aoki K, Sugiura S, Nakayama E, Itakura K, Aizawa M. Letter: HL-A5 and Behcet's disease. Lancet. (1973) 2:1383-4. doi: 10.1016/S0140-6736(73)93343-6

59. Verity DH, Wallace GR, Vaughan RW, Stanford M. Behcet's disease: from Hippocrates to the third millennium. Br J Ophthalmol. (2003) 87:1175-83. doi: 10.1136/bjo.87.9.1175

60. Petrushkin H, Norman PJ, Lougee E, Parham P, Wallace G, Stanford MR, et al. KIR3DL1/S1 allotypes contribute differentially to the development of behcet disease. J Immunol. (2019) 203:1629-35. doi: 10.4049/jimmunol.18 01178

61. Sheikh NS, Sheikh AS, Sheikh AA, Yahya S, Rafi-U-Shan, Lateef M. Seroprevalence of hepatitis B virus infection in Balochistan Province of Pakistan. Saudi J Gastroenterol. (2011) 17:180-4. doi: 10.4103/1319-3767.80380

62. Rahimi Foroushani A, Farzianpour F, Tavana A, Rasouli J, Hosseini S. The 10year trend of TB rate in West Azerbaijan Province, Iran from 2001 to 2010. Iran J Public Health. (2014) 43:778-86.

63. WHO. Global Tuberculosis Report 2019. Geneva: World Health Organization (2019).

64. Mbiribindi B, Mukherjee S, Wellington D, Das J, Khakoo SI. Spatial clustering of receptors and signaling molecules regulates NK cell response to peptide repertoire changes. Front Immunol. (2019) 10:605. doi: 10.3389/fimmu.2019.02370

65. Sim MJW, Rajagopalan S, Altmann DM, Boyton RJ, Sun PD, Long EO. Human NK cell receptor KIR2DS4 detects a conserved bacterial epitope presented by HLA-C. Proc Natl Acad Sci USA. (2019) 116:201903781. doi: $10.1073 /$ pnas. 1903781116

66. Abi-Rached L, Jobin MJ, Kulkarni S, McWhinnie A, Dalva K, Gragert L, et al. The shaping of modern human immune systems by multiregional admixture with archaic humans. Science. (2011) 334:89-94. doi: 10.1126/science.1209202 
67. Mehrjoo Z, Fattahi Z, Beheshtian M, Mohseni M, Poustchi H, Ardalani $F$, et al. Distinct genetic variation and heterogeneity of the Iranian population. PLoS Genet. (2019) 15:e1008385. doi: 10.1371/journal.pgen.10 08385

68. Ashouri E, Farjadian S, Reed EF, Ghaderi A, Rajalingam R. KIR gene content diversity in four Iranian populations. Immunogenetics. (2009) 61:483-92. doi: 10.1007/s00251-009-0378-7

69. Tajik N, Shahsavar F, Mousavi T, Radjabzadeh MF. Distribution of KIR genes in the Iranian population. Tissue Antigens. (2009) 74:22-31. doi: 10.1111/j.1399-0039.2009.01263.x

70. Hiby SE, Ashrafian-Bonab M, Farrell L, Single RM, Balloux F, Carrington M, et al. Distribution of killer cell immunoglobulin-like receptors (KIR) and their HLA-C ligands in two Iranian populations. Immunogenetics. (2010) 62:65-73. doi: 10.1007/s00251-009-0408-5

71. Solgi G, Ghafari H, Ashouri E, Alimoghdam K, Rajalingam R, Amirzargar A. (2011). Comparison of KIR gene content profiles revealed a difference between northern and southern Persians in the distribution of KIR2DS5 and its linked loci. Hum Immunol. 72:1079-83. doi: 10.1016/j.humimm.2011.08.002

Conflict of Interest: The authors declare that the research was conducted in the absence of any commercial or financial relationships that could be construed as a potential conflict of interest.

Copyright (C) 2020 Alicata, Ashouri, Nemat-Gorgani, Guethlein, Marin, Tao, Moretta, Hollenbach, Trowsdale, Traherne, Ghaderi, Parham and Norman. This is an open-access article distributed under the terms of the Creative Commons Attribution License (CC BY). The use, distribution or reproduction in other forums is permitted, provided the original author(s) and the copyright owner(s) are credited and that the original publication in this journal is cited, in accordance with accepted academic practice. No use, distribution or reproduction is permitted which does not comply with these terms. 